\title{
Phase II study of capecitabine and trastuzumab combination chemotherapy in patients with HER2 overexpressing metastatic breast cancers resistant to both anthracyclines and taxanes
}

\author{
Takanori Ishida - Takayoshi Kiba - Motohiro Takeda $\cdot$ Kotone Matsuyama • \\ Satoshi Teramukai $\cdot$ Ryota Ishiwata $\cdot$ Norikazu Masuda $\cdot$ Yuichi Takatsuka • \\ Shinzaburo Noguchi · Chikashi Ishioka • Masanori Fukushima • Noriaki Ohuchi
}

Received: 27 August 2008 / Accepted: 20 November 2008 / Published online: 12 December 2008

(C) The Author(s) 2008. This article is published with open access at Springerlink.com

\begin{abstract}
Purpose The purpose of this study was to investigate the activity of capecitabine and trastuzumab in patients with HER2-overexpressing metastatic breast caner resistant to both anthracyclines and taxanes.

Method From June 2003 and May 2006, 40 female patients with measurable or assessable metastatic breast cancer were enrolled and data from 38 patients were reviewed extramurally and analyzed. Patients were treated
\end{abstract}

T. Ishida $\cdot$ M. Takeda $\cdot$ N. Ohuchi $(\square)$

Department of Surgical Oncology,

Tohoku University School of Medicine,

1-1 Seiryo-machi, Aoba-ku, Sendai 980-8574, Japan

e-mail:noriakio@mail.tains.tohoku.ac.jp

T. Kiba $\cdot$ K. Matsuyama $\cdot$ S. Teramukai $\cdot$ R. Ishiwata $\cdot$

M. Fukushima

Translational Research Informatics Center, Kobe, Japan

K. Matsuyama $\cdot$ S. Teramukai $\cdot$ M. Fukushima

Department of Clinical Trial Design and Management,

Graduate School of Medicine, Kyoto University,

Kyoto, Japan

N. Masuda

Department of Surgery, Osaka National Hospital, Osaka, Japan

Y. Takatsuka

Department of Surgery, Kansai Rosai Hospital, Hyogo, Japan

\section{S. Noguchi}

Department of Breast and Endocrine Surgery,

Graduate School of Medicine, Osaka University,

Osaka, Japan

C. Ishioka

Department of Clinical Oncology,

Institute of Developing, Aging and Cancer,

Tohoku University, Sendai, Japan with weekly trastuzumab given at a dose of $2 \mathrm{mg} / \mathrm{kg} / \mathrm{day}$ over $90 \mathrm{~min}(4 \mathrm{mg} / \mathrm{kg} / \mathrm{day}$ on the first infusion) and capecitabine given at a dose $1,657 \mathrm{mg} / \mathrm{m}^{2} /$ day during 21 days with a subsequent pause of 7 days. This cycle was repeated every 28 days. The primary endpoint was overall survival and secondary endpoints were progression-free survival and response rate.

Result A median of 4.5 cycles (range 1-9 cycles) were delivered. The median age was 53 (range 30-69 years). Median overall survival and progression-free survival was 22.3 and 4.1 months, respectively. Survival rate at 1 and 2 year was 81.6 and $47.4 \%$, respectively. Response rate was $18.4 \%$ (95\% CI, 7.7-34.3\%). All evaluable patients have responded with two CR (5.3\%), 5 PR (13.2\%), $20 \mathrm{SD}$ (52.6\%), 8 PD (21.1\%) and $3 \mathrm{NE}(7.9 \%)$. Regarding the hematological toxicities, grade $1 / 2 / 3$ neutropenia, grade $1 / 2$ anemia, grade 1 thrombocytopenia and grade $1 / 2$ liver dysfunction were also common. No treatment-related death was reported.

Conclusion The combination of capecitabine and trastuzumab is active and well-tolerated in patients with HER2overexpressing breast caner resistant to both anthracyclines and taxanes.

Keywords Phase II study · Capecitabine · Trastuzumab . Metastatic breast caner

$\begin{array}{ll}\text { Abbreviations } \\ \text { BCIRG } & \begin{array}{l}\text { Breast Cancer International Research Group } \\ \text { CI }\end{array} \\ \text { CMF } & \begin{array}{l}\text { Cyclophosphamide, methotrexate } \\ \text { and fluorouracil }\end{array} \\ \text { ECOG } & \text { Eastern Cooperative Oncology Group } \\ \text { ER } & \text { Estrogen receptor } \\ \text { FU } & \text { Fluorouracil }\end{array}$




$\begin{array}{ll}\text { HER2 } & \text { Epidermal growth factor receptor } 2 \\ \text { IHC } & \text { Immunohistochemistry } \\ \text { FISH } & \text { Fluorescence in situ hybridization } \\ \text { MUGA } & \text { Multigated acquisition } \\ \text { PgR } & \text { Progesterone receptor } \\ \text { RECIST } & \text { Response evaluation criteria in solid tumors }\end{array}$

\section{Introduction}

Despite improvements in survivability of nonmetastatic breast cancer patients over the past 25 years, particularly for both estrogen receptor (ER)-positive and human epidermal growth factor receptor 2 (HER2)-positive disease, metastatic breast cancer remains an incurable disease $[1,2]$. When the disease recurred, the decision to choose a certain therapy is usually based on tumor biology, symptoms, metastatic pattern, time to disease recurrence, and patient desire [3].

For metastatic breast cancer the initial treatment with anthracycline-based chemotherapy and/or taxane-based therapy is considered as standard [4,5], whereas the outcome is still poor at present. Therefore, the new avenue for breakthrough in treatments is required to provide. One of the possible approaches is to use molecular targeting therapy. Breast cancers that make high levels of the transmembrane protein kinase HER2 (i.e., those that overexpress HER2) have a poorer prognosis as compared to those that either do not make this protein or make lower levels [6]. It is important that overexpression of HER 2 also identifies those women who may benefit from the targeted drug trastuzumab, and those who do better with chemotherapy regimens that contain a drug of the anthracycline class [6]. The humanized monoclonal antibody trastuzumab, which targets the human HER2, is an effective treatment for patients with HER2 overexpression, which comprises approximately $15-25 \%$ of all breast cancers [7, 8]. Meanwhile, capecitabine ( $\mathrm{N}^{4}$-pentyloxycarbonyl-5'deoxy-5-fluorocytidine), an orally administered prodrug of fluorouracil (FU), is also a highly active and well-tolerated treatment option for metastatic breast cancer. Capecitabine is the therapy specifically approved for anthracycline- and taxaneexposed patients, a setting that is becoming increasingly important as more patients have recurrent metastatic disease after receiving adjuvant anthracycline and taxane therapy [9-12]. The combination of capecitabine and trastuzumab might achieve improved efficacy in patients with HER2-positive metastatic breast cancer without compromising tolerability [13-15].

Recently, Schaller et al. [13] reported that the combination of capecitabine and trastuzumab is highly active in patients with HER2-overexpressing anthracycline- and/or taxane-pretreated breast caner. However, to date, no studies have investigated the activity of capecitabine and trastuzumab in patients with HER2-overexpressing breast caner resistant to both anthracyclines and taxanes. In the present study, we evaluate the activity and safety of this two-agent combination therapy in patient, resistant to both anthracyclines and taxanes.

\section{Patients and methods}

Eligibility criteria

To be eligible for the study, patients had to meet the following criteria: age greater than 20 years and less than 75 years; histologically proven breast cancer with HER2 overexpressing progressive metastatic disease; resistance to both anthracyclines and taxanes for metastatic and advanced disease as described in below, resistance definition section; at least one measurable tumor site (target lesion) with index lesions on physical examination, X-ray, ultrasound, or computed tomography scan; Eastern Cooperative Oncology Group (ECOG) performance status of 0-2; estimated life expectancy $\geq 3$ months; reasonable bone marrow function (neutrophil count $\geq 1,500 / \mu \mathrm{L}$, platelet count $\geq 100,000 / \mu \mathrm{L}$, and hemoglobin levels $\geq 9 \mathrm{~g} / \mathrm{dL}$ ); adequate hepatic and renal function, including AST and ALT twice (in cases of liver metastasis, three times) the upper limit of normal, bilirubin $1.5 \mathrm{~g} / \mathrm{dL}$, alkaline phosphatase 2.5 times the upper limit of normal, serum creatine $1.2 \mathrm{mg} / \mathrm{dL}$, and basal creatine clearance $50 \mathrm{~mL} / \mathrm{min}$; no evidence of cardiac dysfunction (LV ejection fraction $>50 \%$ ). This capecitabine and trastuzumab combination regimen was eligible for patients in third line of therapy, resistant to both anthracyclines and taxanes. Hormonal therapy, in the neoadjuvant or adjuvant setting or for advanced disease, was permitted, but concomitant hormone therapy was not allowed. Moreover, prior trastuzumab was allowed. Brain or leptomeningeal involvement was not allowed. Written informed consent was obtained before registration. The HER2 status was assessed at study entry by immunohistochemistry (IHC) and/or fluorescence in situ hybridization (FISH). Patients with HER2-receptor overexpression at the 3+ level (Hercep Test; DakoCytomation, Capenteria, CA, USA) were immediately eligible for inclusion. A HER2 expression at the $2+$ level required confirmation by the proof of a HER 2 gene amplification by FISH. HER2 testing was performed on a sample of the primary tumor or a biopsy of a metastatic site. HER2 status was examined by the pathologists of each institution participated in this study. The FISH ratio was assessed as the number of genes proportional to the number of centromeres. The HER2 was considered amplified when the FISH signal ratio of HER2 was 2 and more. Exclusion criteria included pretreatment 
with capecitabine (Xeloda; Hoffman La, Rosche AG); hypersensitivity to trastuzumab (Herceptin; Hoffman-La Rosche AG, Basal, Switzerland), fluoropyrimidines, capecitabine, or any other substance of the drug preparation; known lack of dihydropyrimidine dehydrogenase; local resection or irradiation of the marker lesion after study entry; additional systemic antitumor therapy study; pregnancy or breastfeeding.

All data were managed and analyzed in a central data coordinating division located at the Foundation for Biological Research and Innovation, Translational Research Informatics Center, Kobe, Japan.

\section{Definition of both anthracycline and taxane resistance}

We used Ando's definition [16] for reference to determine the primary resistance and secondary resistance to chemotherapeutic agents. All patients must not have received only anthracyclines, but also taxanes for metastatic disease. Primary resistance to anthracycline or taxane was defined as progressive disease during or within 6 months after completion of anthracycline or taxane, respectively. Patients without any documented tumor response to first-line chemotherapy that included anthracyclines or taxanes for metastatic disease also were classified as having primary resistance. Patients whose disease progressed more than 6 months after completion of anthracycline or taxane were treated as a first-line regimen for metastatic disease. Secondary resistance was defined as disease progression among 6-12 months after a documented clinical response to first-line chemotherapy with anthracyclines or taxanes for metastatic disease. Secondary resistance was further divided into three categories as follows: (a) absolute resistance: disease progression during treatment with regimens that contained anthracycline or taxane after a period after completion of the chemotherapy; (b) relative resistance: disease progression within 6 months after complete of the chemotherapy; and (c) sensitive regrowth: disease progression more than 12 months after completion of the chemotherapy.

\section{Therapy}

Trastuzumab was administered at an initial dose of $4 \mathrm{mg} / \mathrm{kg}$ body weight and was administered subsequently at weekly doses of $2 \mathrm{mg} / \mathrm{kg}$ body weight during $90 \mathrm{~min}$. Capecitabine was administered during 21 days with a subsequent pause of 7 days. The daily dose was $1,657 \mathrm{mg} / \mathrm{m}^{2}$ administered in equal parts in the morning and in the evening. This cycle was repeated every 28 days for six cycles. Trastuzumab was discontinued while capecitabine was held. When capecitabine was withdrawn, a new treatment cycle was considered. Trastuzumab and capecitabine were administered until disease progression or unacceptable toxicity.
If capecitabine-associated toxicity occurred, dosage reduction and delayed were permitted.

1. If a grade 2 toxicity occurred, the therapy was interrupted immediately until the symptoms disappeared completely. At that time, the medication was continued at a $75 \%$ level until six cycles. The level was never increased. If a grade 2 or 3 toxicity occurred again, this process was allowed once more until six cycles, at which point the medication was continued at a $50 \%$ level. The level was never increased. If a grade 4 toxicity occurred again, the therapy was interrupted immediately. The treatment was discontinued when the patient developed signs of toxicity for a third time.

2. At the beginning of the treatment, if a grade 3 toxicity occurred, the therapy was stopped immediately until the symptoms disappeared completely. At that time, the medication was continued at a 50\% level until six cycles. The level was never increased. If a grade $\geq 2$ toxicity occurred again, the treatment was discontinued.

3. At the beginning of the treatment, if a grade 4 toxicity occurred, the therapy was stopped immediately.

A dose modification of trastuzumab was not allowed. Mild antiemetic drugs, such as metoclopramide and dexamethasone, and mild antidiarrheal drugs, such as loperamide hydrochloride were administered, if necessary. Trastuzumab was discontinued if patients developed congestive heart failure or the LVEF fell below $45 \%$. The decision to discontinue trastuzumab at that point was discussed with the patient after the risks and potential benefits of trastuzumab therapy were assessed. Granulocyte colony-stimulating factor, to prevent febrile neutropenia was allowed, if grade $\geq 3$ leukopenia occurred, and blood or platelet transfusion was allowed, if grade $\geq 3$ anemia or thrombocytopenia occurred.

\section{Assessment}

The pretreatment evaluation included medical history and physical examination, complete blood cell count, serum chemistries, liver function tests, ECG, echocardiography, tumor marker evaluation (CA15-3, CEA), hormone receptor status (ER, PgR, HER2), and staging studies appropriate to define the extent of metastatic disease, which included chest X-ray, abdominal ultrasound, brain, thoracic and/or abdominal computed tomography scan, and bone scan. Antitumor activity was evaluated every two cycles on all measurable lesions, and all patients were scheduled for at least a 2-week treatment to be eligible for assessment of tumor response. In patients with tumor response or stable disease, the treatment was planned to be continued for up to six cycles; thereafter, maintenance or no therapy was based 
on the clinician's choice. After the completion of the treatment plan, the patients were monitored every two cycles. Clinical monitoring, complete blood cell count, serum chemistries, and liver function tests were performed every 2 weeks until six cycles, and thereafter every 12 weeks. Repeated multigated acquisition (MUGAs) or echocardiograms were performed after completion of cycle 2,4 , and 6 , and thereafter every 12 weeks, if the medication is continued. Patients were evaluated for toxicity, graded according to the National Cancer Institute Common Toxicity Criteria version 2.0 [17].

Tumor response was evaluated according to the response evaluation criteria in solid tumors (RECIST) [18]. Progression-free survival was defined from the first day of treatment to the identification date of recurrence of cancer or death from any cause. Overall survival was dated from the first day of treatment until death or was censored on the date of the last follow-up appointment.

\section{Statistical analysis}

The primary endpoint of the study was the assessment of the overall survival. Secondary endpoints were the determination of the progression-free survival and response rate. In this trial, the targeted patients resistant to both anthracycline and taxane had highly dismal disease, whose 1 year survival was estimated $<33 \%$ [16], thereby overall survival was chosen for the primary endpoint. The recent paper [19] reported that overall survival should be viewed as the endpoint of choice to assess the efficacy of new treatments in advanced breast cancer. The regimen would have been considered promising if the true 1-year survival were $50 \%$ or higher in conjunction with acceptable toxicity, and would be considered of no further interest if the true 1-year survival were $33 \%$ or lower. With 63 patients, the power of a two-sided 0.05 -level test is $80 \%$. However, the power was reduced to $62 \%$ because only 40 patients were enrolled in the study. Survival curves were estimated using the Kaplan-Meier method. To test the differences of the survival curves among subgroup of patients, the log-rank test was used. All statistical analyses were performed using the SAS version 9.1(SAS Institute, Inc, Cary, NC, USA). All tests were two-sided, and a $P<0.05$ was considered statistically significant.

\section{Results}

Patients characteristics

From June 2003 to May 2006, 40 patients with metastatic and HER2-overexpressing breast cancer, which was defined as the primary resistance or secondary resistance to both anthracycline and taxane, were entered onto the study. One patient was declared ineligible after registration: one patient was treated off-protocol immediately after enrollment. Thirty-eight patients were reviewed extramurally and analyzed. The demographic data, numbers of metastatic tumor, and prior therapies are listed in Table 1. The median age was 53 years (range 30-69 years), and Eastern Cooperative Oncology Group performance status was good ( 0 or 1 in $95 \%$ of cases). Regarding prior treatments, 18 patients were given anthracycline as neoadjuvant or adjuvant chemotherapy and 19 patients for metastatic disease. In addition, 9 patients were given taxane as neoadjuvant or adjuvant chemotherapy and 28 patients for metastatic disease. Resistance to previous chemotherapies (anthracycline/taxane) was 7 patients (18\%) with primary resistance/ primary resistance, 11 with (29\%) with primary/secondary, 6 (16\%) with secondary/primary, 11 (29\%) with secondary/ secondary, and 3 (8\%) with unknown, respectively. Predominate sites of metastasis were found in 37 cases (97\%). 27 patients $(71 \%)$ had one metastatic site, and 10 patients (26\%) had multiple metastases involving two or more organ systems; 17 lung (45\%), 10 liver (26\%), 5 bone (13\%), 2 skin (5\%), and 4 other sites (10.5\%), respectively. $34(90 \%)$ of the patients had invasive ductal carcinomas, 3 patients $(8 \%)$ had cancers of other types, but the histopathological type of one patient (3\%) was unknown. Seventy nine percent of patients had a past history of prior therapy of trastuzumab.

\section{Treatment activity}

A median of 4.5 cycles (range 1-9 cycles) of treatment were delivered. The median dose of capecitabine was $227,400 \mathrm{mg} /$ body (range 2,400-453,600 mg/body) and the median dose of trastuzumab was $1.28 \mathrm{mg} / \mathrm{m}^{2} /$ week (range $0.31-1.51 \mathrm{mg} / \mathrm{m}^{2} /$ week). Median follow-up time was 22.4 months (range 0.4-50.6 months). Median overall survival and progression-free survival of the entire group were 22.3 and 4.1 months, respectively (Fig. 1). Survival at 1 and 2 year was $81.6 \%$ (95\% CI, 65.2-90.8\%) and $47.4 \%$ (95\% CI, 31.0-62.1\%), respectively. The best responses recorded for each patient are listed in Table 2. A response rate (CR or PR) was recorded in 7 of 38 women $(18.4 \%$; 95\% CI, 7.7-34\%): 2 patients (5\%) achieved a CR, and 5 patients $(13 \%)$ achieved a PR. SD was observed in 20 patients $(53 \%)$, and PD was observed in $8(21 \%)$. Clinical benefit rate (CBR: $\mathrm{CR}$ or PR or $\mathrm{SD}>/=24$ weeks) was $21.1 \%$ (95\% CI (confidence interval), 9.6-37.3\%). All patients were treated previously with both anthracyclines and taxanes. According to the previous treatment, a tumor response was obtained in $18(47 \%)$ of 38 cases previously submitted to anthracycline-containing regimens and in 22 $(58 \%)$ of 38 cases submitted to taxane-containing regimens. 
Table 1 Patient Characteristics

\begin{tabular}{|c|c|c|}
\hline & $\begin{array}{l}\text { No. of } \\
\text { patients }\end{array}$ & $\%$ \\
\hline No. & 38 & \\
\hline \multicolumn{3}{|l|}{ Age, years } \\
\hline Median & 53 & \\
\hline Range & $30-69$ & \\
\hline \multicolumn{3}{|l|}{ Performance status ${ }^{\mathrm{a}}$} \\
\hline 0 & 31 & 81.6 \\
\hline 1 & 5 & 13.2 \\
\hline 2 & 2 & 5.3 \\
\hline \multicolumn{3}{|l|}{ Menopausal status } \\
\hline Premenopause & 12 & 31.6 \\
\hline Postmenopause & 26 & 68.4 \\
\hline \multicolumn{3}{|l|}{ Receptor status } \\
\hline \multicolumn{3}{|l|}{ Estrogen receptor } \\
\hline Positive & 7 & 18.4 \\
\hline Negative & 31 & 81.6 \\
\hline \multicolumn{3}{|l|}{ Progesterone receptor } \\
\hline Positive & 6 & 15.8 \\
\hline Negative & 31 & 81.6 \\
\hline Unknown & 1 & 2.6 \\
\hline \multicolumn{3}{|l|}{$\begin{array}{l}\text { Resistance to previous chemotherapies } \\
\text { (Anthracycline/Taxane) }\end{array}$} \\
\hline Primary resistance/Primary resistance & 7 & 18.4 \\
\hline Primary resistance/Secondary resistance & 11 & 29.0 \\
\hline Secondary resistance/Primary resistance & 6 & 15.8 \\
\hline $\begin{array}{l}\text { Secondary resistance/Secondary } \\
\text { resistance }\end{array}$ & 11 & 29.0 \\
\hline Unknown & 3 & 7.9 \\
\hline \multicolumn{3}{|l|}{ Prior trastuzumab } \\
\hline Yes & 30 & 78.9 \\
\hline No & 8 & 21.2 \\
\hline \multicolumn{3}{|l|}{ Histology } \\
\hline Invasive ductal carcinomas & 34 & 89.5 \\
\hline Other & 3 & 7.9 \\
\hline Unknown & 1 & 2.6 \\
\hline \multicolumn{3}{|l|}{ Number of metastasis } \\
\hline 1 & 27 & 71.1 \\
\hline$\geq 2$ & 10 & 26.3 \\
\hline Unknown & 1 & 2.6 \\
\hline \multicolumn{3}{|l|}{ Primary metastatic sites } \\
\hline Lung & 17 & 44.7 \\
\hline Liver & 10 & 26.3 \\
\hline Bone & 5 & 13.2 \\
\hline Skin & 2 & 5.3 \\
\hline Peritoneum & 1 & 2.6 \\
\hline Mediastinum & 1 & 2.6 \\
\hline Pleura & 1 & 2.6 \\
\hline Unknown & 1 & 2.6 \\
\hline
\end{tabular}

${ }^{a}$ Eastern Cooperative Oncology Group

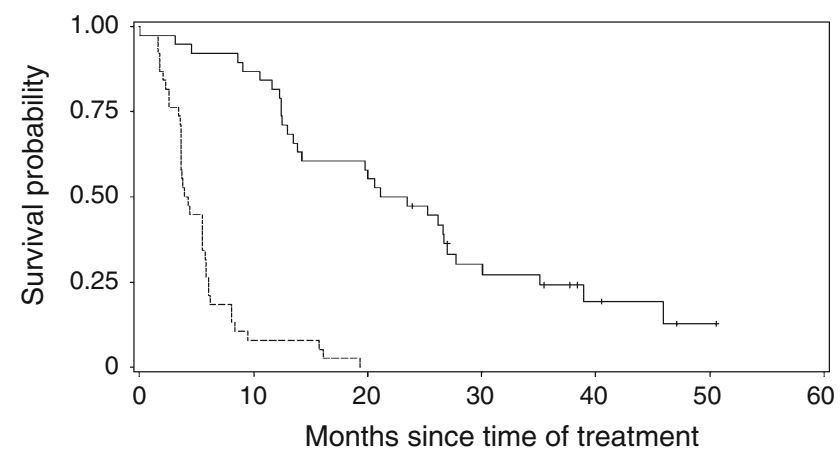

Fig. 1 Overall survival curve (solid line) and progression-free survival curve (dot line) of patients with HER2 overexpressing metastatic breast cancers with capecitabine and trastuzumab combination chemotherapy resistant to both anthracyclines and taxanes

Table 2 Response to therapy $(n=38)$

\begin{tabular}{llr}
\hline Response & No. of Patients & \multicolumn{1}{c}{$\%$} \\
\hline Complete response & 2 & 5.3 \\
Partial response & 5 & 13.2 \\
Stable disease & 20 & 52.6 \\
Progressive disease & 8 & 21.1 \\
Not evaluated & 3 & 7.9 \\
Response rate & $18.4 \%(95 \% \mathrm{CI}$, \\
& $7.7-34.3 \%)$ & \\
Clinical benefit rate & $21.1 \%(95 \% \mathrm{CI}$, & \\
$\quad(\mathrm{CBR}=\mathrm{CR}+\mathrm{PR}+\mathrm{SD}>/=24$ weeks $)$ & $9.6-37.3 \%)$ &
\end{tabular}

$C I$ confidence interval, $C R$ complete response, $P R$ partial response, $S D$ stable disease for 6 weeks, $P D$ progressive disease

$13(34 \%)$ or $10(26 \%)$ of 38 patients had progressive disease during the treatment with anthracyclines or taxanes, respectively. There was no difference in overall survival in patients with and without history of trastuzumab $(P=0.80)$.

Anthracycline or taxane resistance and response to capecitabine and trastuzumab combination chemotherapy

The response rates of patients with primary and secondary resistance of anthracycline and taxane are shown in Table 3. There was no difference in response rate between primary and secondary resistance in anthracycline and taxane pretreated patients, respectively $(P=0.73)$.

Toxicity

Associated side effects are reported in Table 4; on the whole, they were mild. There were no treatment-related deaths. Regarding the hematological toxicities, neutropenia occurred in 19 patients but was grade 3 only in 2 patients $(5 \%)$. Thrombocytopenia was rather uncommon, occurring 
Table 3 Response rates classified by anthracycline or taxane resistance category

\begin{tabular}{lllll}
\hline $\begin{array}{l}\text { Anthracycline/ } \\
\text { Taxane }\end{array}$ & $\begin{array}{l}\text { Primary resistance/ } \\
\text { Primary resistance }\end{array}$ & $\begin{array}{l}\text { Primary resistance/ } \\
\text { Secondary resistance }\end{array}$ & $\begin{array}{l}\text { Secondary resistance/ } \\
\text { Primary resistance }\end{array}$ & $\begin{array}{l}\text { Secondary resistance/ } \\
\text { Secondary resistance }\end{array}$ \\
\hline No. of patients & 7 & 11 & 6 & 11 \\
Response rate (\%) & $1 / 7(14.3)$ & $2 / 11(18.2)$ & $2 / 6(33.3)$ & $1 / 11(9.1)$ \\
$95 \%$ CI & $0.4-57.9$ & $2.3-51.8$ & $4.3-77.7$ & $0.2-41.3$ \\
\hline
\end{tabular}

$C$ Confidence interval. There was no difference in response rate among each group $(P=0.73)$

(grade 1) in only two case $(5 \%)$. Seven patients developed grade 2 anemia (18\%). Grade $\geq 4$ hematologic toxicity was not observed. No patient developed a documented infection, and none required hospitalization owing to toxicity. Moreover, grade 1/2 liver dysfunction (elevated AST, ALT, ALP, $\gamma$-GTP, and T-bil) was common (45, 34, 50, 34, and $42 \%$ ), and grade $1 / 2$ hypercalcemia and hypoalbuminemia was also common (45 and $32 \%$ ). Regarding the nonhematological toxicities, the most common adverse events were hand-foot syndrome (grade1/2/3 in 24; 63\%), fatigue (grade $1 / 2$ in $12 ; 32 \%$ ), and diarrhea (grade $1 / 2 / 3$ in 9 ; 24\%). Mucositis occurred in 11 patients (grade 1 in 10; $29 \%$ ). Serious adverse effects occurred in three patients (7.9\%, 95\% CI, 1.7-21.4\%): 2 died of breast cancer and one died of accidental asphyxia. Twenty-three patients discontinued therapy because of disease progression in 13 , physician's discretion in 4 , adverse effects in 4 (grade 3 neutropenia at cycle 2 , grade 2 general fatigue at cycle 2 , and grade 3 hand-foot syndrome at cycle 2 and 5), and death in 2.

\section{Discussion}

We have detected three reports concerning the activity of capecitabine and trastuzumab in anthracyclines or taxanespretreated patients with HER2-overexpressing breast caner [13-15]. However, there is no prospective study describing the activity of capecitabine and trastuzumab in patients with HER2-overexpressing breast caner resistant to both anthracyclines and taxanes. This is the first report that the combination of capecitabine and trastuzumab is active in patients with HER2-overexpressing breast caner resistant to both anthracycline and taxane. Moreover, we could observed that among the patients with the primary and secondary resistant to anthracycline and taxane, there was no difference in response rate.

In recent studies of various chemotherapeutic agents for breast cancer patients after failure of both anthracycline and taxanes, the median overall survival was 12.8 months with capecitabine alone [8], 7.8 months with gemcitabine alone [20], 7.4 months with gemcitabine and cisplatin [21], and 10.3 months with gemcitabine and pemetrexed [22]. In the present study, we suggested that the median overall survival was prolonged to 22.3 months with the combination of capecitabine and trastuzumab for patients resistant to both anthracyclines and taxanes. Therefore, we speculate that trastuzumab with capecitabine can increase the overall survival in patients with these HER2 overexpressing metastatic breast cancers. For such category of patients, one phase II study of trastuzumab plus gemcitabine in both anthracycline and taxane-pretreated patients with metastatic breast cancer, the median overall survival was reported to be 14.7 months [23]. Further, Fig. 1 shows that $79 \%$ of the patients enrolled in the present study had a past history of trastuzumab administration. Very recently, Minckwitz et al. [24] reported a higher efficacy for continuing trastuzumab beyond trastuzumab progression when second-line chemotherapy with capecitabine was initiated.

Until recently relative few clinical data were available concerning the combination of trastuzumab with capecitabine. Osako et al. [14] retrospectively evaluated the efficacy and safety of combination therapy of trastuzumab plus capecitabine in heavily pretreated patients with HER2-positive metastatic breast cancer. They investigated objective response rate, clinical benefit rate, and time-to-treatment failure according to RECIST. A total of 49 patients were assessed and median follow-up time of patients was 16.2 months (1.4-43.5 months). Objective response rate was $16 \%$ (95\% CI: 7-30\%) and clinical benefit rate was 47\% (95\% CI: 32-62\%). Median time-to-treatment failure was 5.4 months. Osako's report suggests the combination therapy of trastuzumab plus capecitabine was active and tolerable for heavily pretreated patients with HER2-positive metastatic breast cancer. The combination therapy with capecitabine and trastuzumab has been used by the other investigators as a first-line [25] or second-line [13] treatment for metastasis from breast cancer. Patients receiving trastuzumab and capecitabine as first-line therapy had a longer time to disease progression than did patients receiving this treatment as second- or third-line therapy (median time to disease progression, 9.3 vs. 6.7 months, $P<0.05$ ), but did not have longer overall survival (median overall survival, 26.0 vs. 28.0 months).

As to the toxicities of the combination therapy with capecitabine and trastuzumab, Schaller et al. [13] reported 
Table 4 Toxicity results

\begin{tabular}{|c|c|c|c|c|c|}
\hline Table 4 Toxicity results & \multirow[t]{2}{*}{ Toxicity grade ${ }^{\mathrm{a}}$} & \multirow{2}{*}{$\begin{array}{l}\text { Grade } 1 \\
\text { No. of } \\
\text { patients }(\%)\end{array}$} & \multirow{2}{*}{$\begin{array}{l}\text { Grade } 2 \\
\text { No. of } \\
\text { patients (\%) }\end{array}$} & \multirow{2}{*}{$\begin{array}{l}\text { Grade } 3 \\
\text { No. of } \\
\text { patients }(\%)\end{array}$} & \multirow{2}{*}{$\begin{array}{l}\text { Grade } 4 \\
\text { No. of } \\
\text { patients (\%) }\end{array}$} \\
\hline & & & & & \\
\hline & \multicolumn{5}{|l|}{ Hematological toxicity } \\
\hline & Anemia & $1(2.6)$ & $7(18.4)$ & 0 & 0 \\
\hline & Leucocytopenia & $1(2.6)$ & $6(15.8)$ & 0 & 0 \\
\hline & Neutropenia & $11(28.9)$ & $6(15.8)$ & $2(5.3)$ & 0 \\
\hline & Thrombocytopenia & $2(5.3)$ & 0 & 0 & 0 \\
\hline & Elevated ALP & $17(44.7)$ & $2(5.3)$ & 0 & 0 \\
\hline & Elevated AST & $14(36.8)$ & $3(7.9)$ & 0 & 0 \\
\hline & Elevated ALT & $12(31.6)$ & $1(2.6)$ & 0 & 0 \\
\hline & Elevated $\gamma$-GTP & $8(21.1)$ & $3(7.9)$ & $2(5.3)$ & 0 \\
\hline & Elevated T-Bil & $11(28.9)$ & $5(13.2)$ & 0 & 0 \\
\hline & Elevated creatinine & $1(2.6)$ & 0 & 0 & 0 \\
\hline & Hypercalcemia & $16(42.1)$ & $1(2.6)$ & 0 & 0 \\
\hline & Hypoalbuminemia & $12(31.6)$ & 0 & 0 & 0 \\
\hline & \multicolumn{5}{|l|}{ Nonhematological toxicity } \\
\hline & Hand-foot syndrome & $16(42.1)$ & $5(13.2)$ & $3(7.9)$ & 0 \\
\hline & Mucositis & $11(28.9)$ & 0 & 0 & 0 \\
\hline & Nausea & $8(21.1)$ & 0 & 0 & 0 \\
\hline & Vomiting & $4(10.5)$ & 0 & 0 & 0 \\
\hline & Diarrhea & $7(18.4)$ & $1(2.6)$ & $1(2.6)$ & 0 \\
\hline & Constipation & 0 & 0 & $1(2.6)$ & 0 \\
\hline & Abdominal pain & $1(2.6)$ & 0 & 0 & 0 \\
\hline & Edema & $3(7.9)$ & 0 & 0 & 0 \\
\hline & Rash & $1(2.6)$ & 0 & 0 & 0 \\
\hline & Hyperpigmentation & $5(13.2)$ & 0 & 0 & 0 \\
\hline & Pruritus & $1(2.6)$ & 0 & 0 & 0 \\
\hline & Injection site reaction & $1(2.6)$ & 0 & 0 & 0 \\
\hline & Nail changes & $1(2.6)$ & $1(2.6)$ & 0 & 0 \\
\hline & Ulceration & $1(2.6)$ & 0 & 0 & 0 \\
\hline & Cervical pain & $1(2.6)$ & 0 & 0 & 0 \\
\hline & Chest pain & $2(5.3)$ & 0 & 0 & 0 \\
\hline & Cough & $2(5.3)$ & $1(2.6)$ & 0 & 0 \\
\hline & Sputum & 0 & $1(2.6)$ & 0 & 0 \\
\hline & Dyspnea & 0 & $1(2.6)$ & 0 & 0 \\
\hline & Fever & $3(7.9)$ & $1(2.6)$ & 0 & 0 \\
\hline & Fatigue & $10(26.3)$ & $2(5.3)$ & 0 & 0 \\
\hline & Appetite loss & $2(5.3)$ & $1(2.6)$ & 0 & 0 \\
\hline & Weight loss & 0 & $1(2.6)$ & 0 & 0 \\
\hline & Headache & $5(13.2)$ & 0 & 0 & 0 \\
\hline & Dizziness & $1(2.6)$ & 0 & 0 & 0 \\
\hline & Voice changes & $1(2.6)$ & 0 & 0 & 0 \\
\hline & Impaired motor function & $4(10.5)$ & 0 & 0 & 0 \\
\hline & Photophobia & 0 & $1(2.6)$ & 0 & 0 \\
\hline & Cataract & 0 & $1(2.6)$ & 0 & 0 \\
\hline & Back pain & $1(2.6)$ & 0 & 0 & 0 \\
\hline${ }^{a}$ According to National & Urinary retention & $1(2.6)$ & 0 & 0 & 0 \\
\hline $\begin{array}{l}\text { Cancer institute common } \\
\text { Toxicity Criteria }\end{array}$ & Pain on urination & $1(2.6)$ & 0 & 0 & 0 \\
\hline
\end{tabular}

a According to National Cancer institute common Toxicity Criteria 
that the safety profile of this combination was favorable for breast cancer patients with HER2-overexpressing anthracycline- and/or taxane-pretreated breast caner. The most common adverse events were pain, hand-foot syndrome, and gastrointestinal toxicities. In the present study, we confirmed that this combination therapy was safe and well tolerated regimen. Moreover, the present study suggested that grade 1/2 liver dysfunction (elevated AST, ALT, ALP, $\gamma$-GTP, and T-bil) was common in the combination therapy of capecitabine and trastuzumab. As to the hematological toxicities, grade $1 / 2$ anemia occurred in $21 \%$ patients in the present trial versus $68 \%$ in Schaller's trial, but grade 3/4 anemia in $5 \%$ versus $8 \%$ patients. Moreover, regarding the nonhematological toxicities, grade $1 / 2$ hand-foot syndrome, one of the most common adverse events, occurred in 55\% patients in this present trial versus $68 \%$ in Schaller's trial, but grade $3 / 4$ in 8 versus $16 \%$ patients. Because it was reported that no clinically relevant differences in the pharmacokinetics of capecitabine and its key metabolites 5'-DFUR, 5'-DFCR, and 5-FU were found between Japanese and Caucasian patients [26], the lower incidence of toxicity observed in our study may be due to the difference of total doses of capecitabine between the present trial and Schaller's trial: the total dose of the present trial [about $156,586 \mathrm{mg} / \mathrm{m}^{2}: \quad 1,657 \mathrm{mg} / \mathrm{m}^{2} \times 21$ days $\times 4.5 \quad$ (median treatment cycles)] versus that of Schaller's trial (about $280,000 \mathrm{mg} / \mathrm{m}^{2}: \quad 2,500 \mathrm{mg} / \mathrm{m}^{2} \times 14$ days $\times 8 \quad$ (median treatment cycles)). The reason why we selected a dose $1,657 \mathrm{mg} / \mathrm{m}^{2} /$ day during 21 days with a subsequent pause of 7 days as given capecitabine was rigorously based on the previous result in Japan [27]. There were no differences in response rate (20 vs. $20 \%$ ) and median time to disease progression (2.8 vs. 3.0 months) between the different drug administrations from Japan and US [8, 27]. Consistent with this, further investigations are needed to assess the safety in additional clinical trials.

In conclusion, the combination of capecitabine and trastuzumab is active and well-tolerated in patients with HER2-overexpressing breast cancer well defined resistance to both anthracyclines and taxanes. Although at present, the other chemotherapeutic agents such as vinorelbine and oxaliplatin are under way for such category group disease [28], our results suggest that this combination therapy may be established as a third line chemotherapy for these breast cancer patients, by using the overall survival as primary endpoint and the progression-free survival and response rate as secondary endpoints, because the targeted patients in the present study had highly dismal disease.

Acknowledgments We thank Keiko Miyakoda and Tomomi Sakabayashi (Translational Research Informatics Center, Kobe, Japan) for their statistical review and advice.
Open Access This article is distributed under the terms of the Creative Commons Attribution Noncommercial License which permits any noncommercial use, distribution, and reproduction in any medium, provided the original author(s) and source are credited.

\section{Appendix}

The following individuals and institutions participated in this study: N. Ohuchi, MD, T. Ishida, MD, M. Takeda, MD, Tohoku University Hospital, Sendai, Japan; Y. Takatsuka, MD, T. Aihara, MD, Kansai Rosai Hospital, Amagasaki, Japan; N. Masuda, MD, Osaka National Hospital, Osaka, Japan; S. Noguchi, MD, T. Taguchi, MD, Osaka University Hospital, Suita, Japan; R. Nishimura, MD, Kumamoto City Hospital, Kumamoto, Japan; G. Amano, MD, Sakata City Hospital, Sakata, Japan; M. Tamura, MD, M. Takehara, MD, Hokkaido Cancer Center, Sapporo, Japan; T. Ohmura, MD, Sapporo Medical University Hospital, Sapporo, Japan; Y. Narita, MD, Teine Keijinkai Hospital, Sapporo, Japan; M. Kashiwaba, MD, Iwate Medical University Hospital, Morioka, Japan; Y. Kiyosawa, MD, Nakadori General Hospital, Akita, Japan; T. Hashizume, MD, Akita City Hospital, Akita, Japan; S. Kimura, MD, M. Kamiga MD, Yamagata University Hospital, Yamagata, Japan; A. Kikuchi, MD, S. Kudo MD, Yamagata Prefectural Central Hospital, Yamagata, Japan; H. Hirakawa, MD, A. Tazawa MD, Tohoku Kosai Hospital, Sendai, Japan; K. Namiki, MD, R. Yoshida, MD, Osaki Citizen Hospital, Osaki, Japan; T. Nomizu MD, Hoshi General Hospital, Koriyama, Japan; E. Fukuma, MD, Kameda General Hospital, Kamogawa, Japan; N. Yamamoto, MD, Chiba Cancer Center, Chiba, Japan; M. Toi, MD, S. Saji MD, Tokyo Metropolitan Komagome Hospital, Tokyo, Japan; H. Tahara, MD, Y. Takeda, MD, Institute of Medical Science, University of Tokyo, Tokyo, Japan; S. Nakamura, MD, St. Luke's International Hospital, Tokyo, Japan; M. Kusama, MD, Tokyo Medical University Hospital, Tokyo, Japan; T. Asaga, MD, M. Inaba, MD, Kanagawa Cancer Center, Yokohama, Japan; M. Fukuda, MD, H. Ogata, MD, St. Marianna University Hospital, Kawasaki, Japan; K. Iwase, MD, Fujita Health University Hospital, Toyoake, Japan; H. Yoshino, MD, Ishikawa Prefectural Central Hospital, Kanazawa, Japan; E. Shiba, MD, Osaka Kosei Nenkin Hospital, Osaka, Japan; J. Matsuoka, MD, Okayama University Hospital, Okayama, Japan; S. Murakami, MD, Research Institute for Radiation Biology and Medicine, Hiroshima University, Hiroshima, Japan; S. Mitsuyama, MD, Kitakyushu Municipal Medical Center, Kitakyushu, Japan.

\section{References}

1. Ueno M, Kiba T, Nishimura $\mathrm{T}$ et al (2007) Changes in survival during the past two decades for breast cancer at the Kyoto University Hospital. Eur J Surg Oncol 33:696-699 
2. Petrelli F, Cabiddu M, Cazzaniga ME et al (2008) Targeted therapies for the treatment of breast cancer in the post-trastuzumab era. Oncologist 13:373-381

3. Beslija S, Bonneterre J, Burstein H et al (2007) Second consensus on medical treatment of metastatic breast cancer. Ann Oncol 18:215-225

4. Ueno NT, Buzdar AU, Singletary SE (1997) Combined-modality treatment of inflammatory breast carcinoma: twenty years of experience at M. D. Anderson Cancer Center. Cancer Chemother Pharmacol 40:321-329

5. Berg CD, Swain SM (1994) Results of concomitantly administered chemoradiation for locally advanced noninflammatory breast cancer. Semin Radiat Oncol 4:226-235

6. http://www.uptodate.com/patients/content/topic.do?topicKey=cancer $/ 2904$

7. Hynes NE, Stern DF (1994) The biology of erbB-2/neu/HER-2 and its role in cancer. Biochim Biophys Acta 1198:165-184

8. Revillion F, Bonneterre J, Peyrat JP (1998) ERBB2 oncogene in human breast cancer and its clinical significance. Eur J Cancer 34:791-808

9. Blum JL, Jones SE, Buzdar AU et al (1999) Multicenter phase II study of capecitabine in paclitaxel-refractory metastatic breast cancer. J Clin Oncol 17:485-493

10. Blum JL, Dieras V, Lo Russo PM et al (2001) Multicenter, phase II study of capecitabine in taxane-pretreated metastatic breast carcinoma patients. Cancer 92:1759-1768

11. Reichardt P, Von Minckwitz G, Thuss-Patience PC et al (2003) Multicenter phase II study of oral capecitabine (Xeloda(")) in patients with metastatic breast cancer relapsing after treatment with a taxane-containing therapy. Ann Oncol 14:1227-1233

12. Fumoleau P, Largillier R, Clippe C et al (2004) Multicentre, phase II study evaluating capecitabine monotherapy in patients with anthracycline- and taxane-pretreated metastatic breast cancer. Eur J Cancer 40:536-542

13. Schaller G, Fuchs I, Gonsch T et al (2007) Phase II study of capecitabine plus trastuzumab in human epidermal growth factor receptor 2 overexpressing metastatic breast cancer pretreated with anthracyclines or taxanes. J Clin Oncol 25:3246-3250

14. Osako T, Ito Y, Takahashi S et al (2008) Efficacy and safety of trastuzumab plus capecitabine in heavily pretreated patients with HER2-positive metastatic breast cancer. Cancer Chemother Pharmacol 62:159-164

15. Bartsch R, Wenzel C, Altorjai G et al (2007) Capecitabine and trastuzumab in heavily pretreated metastatic breast cancer. J Clin Oncol 25:3853-3858
16. Ando M, Watanabe T, Nagata K et al (2001) Efficacy of docetaxel $60 \mathrm{mg} / \mathrm{m}^{2}$ in patients with metastatic breast cancer according to the status of anthracycline resistance. J Clin Oncol 19:336-342

17. http://ctep.cancer.gov/forms/CTCv20_4-30-992.pdf

18. Therasse P, Arbuck SG, Eisenhauer EA et al (2000) New guidelines to evaluate the response to treatment in solid tumors. European Organization for Research and Treatment of Cancer, National Cancer Institute of the United States, National Cancer Institute of Canada. J Natl Cancer Inst 92:205-216

19. Burzykowski T, Buyse M, Piccart-Gebhart MJ et al (2008) Evaluation of tumor response, disease control, progression-free survival, and time to progression as potential surrogate end points in metastatic breast cancer. J Clin Oncol 26:1987-1992

20. Smorenburg CH, Bontenbal M, Seynaeve C et al (2001) Phase II study of weekly gemcitabine in patients with metastatic breast cancer relapsing or failing both an anthracycline and a taxane. Breast Cancer Res Treat 66:83-87

21. Tas F, Guney N, Derin D et al (2008) Biweekly administration of gemcitabine and cisplatin chemotherapy in patients with anthracycline and taxane-pretreated metastatic breast cancer. Invest New Drugs 26:363-368

22. Ma CX, Steen P, Rowland KM et al (2006) A phase II trial of a combination of pemetrexed and gemcitabine in patients with metastatic breast cancer: an NCCTG study. Ann Oncol 17:226-231

23. O'Shaughnessy JA, Vukelja S, Marsland T et al (2004) Phase II study of trastuzumab plus gemcitabine in chemotherapy-pretreated patients with metastatic breast cancer. Clin Breast Cancer 5:142-147

24. Minckwitz G, Zielinski C, Maarteense E et al (2008) Capecitabine vs. capecitabine + trastuzumab in patients with HER2-positive metastatic breast cancer progressing during trastuzumab treatment: The TBP phase III study (GBG 26/BIG 3-05). J Clin Oncol 26:1025a

25. Xu L, Song S, Zhu J et al (2004) Results of a phase II trial of Herceptin plus Xeloda in patients with previously untreated HER2positive metastatic breast cancer. Breast Cancer Res Treat 88(suppl 1):S128

26. Reigner B, Watanabe T, Schüller J et al (2003) Pharmacokinetics of capecitabine (Xeloda) in Japanese and Caucasian patients with breast cancer. Cancer Chemother Pharmacol 52:193-201

27. Watanabe T, Katsumata N, Sasaki Y et al (1991) A multicenter phase II Trial of Xeloda ${ }^{\mathrm{TM}}$ (Capecitabine) in patients with docetaxel-refractory advanced/metastatic breast cancer. Proc Am Soc Clin Oncol 20:1991a

28. http://www.clinicaltrials.gov 